\title{
ATIVIDADE RESIDUAL DE (IMAZETHAPYR+IMAZAPIC) PARA SORGo GRANÍfERo (Sorghum bicolor) SEMEAdo EM ROTAÇÃo COM O ARROZ IRRIGADO $^{1}$
}

\author{
Field Persistence of (imazethapyr+imazapic) to Grain Sorghum (Sorghum bicolor) Planted in \\ Rotation after Irrigated Rice
}

PINTO, J.J.O. ${ }^{2}$, NOLDIN, J.A. ${ }^{3}$, PINHO, C.F. ${ }^{4}$, ROSSI, F. ${ }^{5}$, GALON, L. ${ }^{6}$ e ALMEIDA, G.F. ${ }^{7}$

\begin{abstract}
RESUMO - Este trabalho teve por objetivo avaliar a atividade residual da mistura formulada dos herbicidas (imazethapyr+imazapic), marca comercial Only, para a cultura do sorgo granifero, cv. BR 304, semeado em rotação, após um, dois e três anos com arroz irrigado, no sistema de produção Clearfield ${ }^{\circledR}(\mathrm{CL})$. Os experimentos foram conduzidos em campo, em área da Universidade Federal de Pelotas, municipio de Capão do Leão-RS. Considerou-se o arroz como a cultura principal, o azevém como cultura sucessora e o sorgo como substituinte do arroz no sistema de rotação. À exceção da primeira semeadura de arroz, em cada ano, todas as culturas foram conduzidas pelo sistema direto. O delineamento experimental foi o de blocos ao acaso, com quatro repetições. Os tratamentos foram arranjados em esquema fatorial, em que o fator A comparou resíduo em diferentes ambientes (anos de cultivo de arroz CL) e o B avaliou o efeito de doses sobre o residual dos herbicidas. O arroz semeado foi o cv. IRGA $422 \mathrm{CL}$, e os tratamentos herbicidas foram doses da mistura formulada de (imazethapyr+imazapic) a $0,(75+25),(112,5+37,5)$ e $(150+50) \mathrm{g}^{-1} \mathrm{a}^{-1}$, acrescidos de Dash a $0,5 \% \mathrm{v} / \mathrm{v}$. Os experimentos ou ambientes foram denominados de A1, A2 e A3, respectivamente para um, dois e três anos de cultivo de arroz irrigado pelo sistema CL. Como espécie indicadora da presença de resíduos dos herbicidas utilizou-se o sorgo granífero, cv. BR 304. As variáveisresposta consideradas foram: população e estatura média das plantas, rendimento biológico, peso de mil grãos e produtividade do sorgo. Quanto a estatura de plantas e peso de mil grãos, ocorreu interação entre os fatores ambiente e dose dos herbicidas; já para as demais variáveis verificou-se significância estatística somente para doses dos herbicidas. Concluise que o cultivo de arroz irrigado no sistema de produção CL deixa resíduos dos herbicidas (imazethapyr+imazapic) no solo, capazes de causar danos irrecuperáveis ao sorgo cultivado em safra subsequente ao arroz.
\end{abstract}

Palavras-chave: arroz-vermelho, arroz Clearfield ${ }^{\circledR}$, imidazolinonas, persistência no solo.

\begin{abstract}
The objective of this research was to evaluate the field persistence of the herbicide Only (imazethapyr+imazapic), to grain sorghum, planted in rotation after one, two or three years of Clearfield ${ }^{\circledR}(C L)$ rice. The field study was carried out at Universidade Federal de Pelotas, Capão do Leão, state of Rio Grande do Sul. Clearfield rice was established as the main crop, Italian ryegrass as a succession crop and grain sorghum, as a rotation crop after CL rice. Except for the first rice crop, all the other cultures were planted as no-till rice. Ryegrass plants were burned down in every experiment using glyphosate $\left(760 \mathrm{~g}\right.$ a.e. $\left.\mathrm{ha}^{-1}\right)$. The experimental design was a factorial with treatments arranged in a complete randomized design, with four replications, where factor $A$ was the number of $C L$ rice seasons and $B$ was the herbicide rate. The rice cultivar was
\end{abstract}

1 Recebido para publicação em 7.10.2008 e na forma revisada em 11.12.2009.

2 Engo-Agr ${ }^{0}$., Dr., Professor da Faculdade de Agronomia da Universidade Federal de Pelotas - UFPel, Campus Capão do Leão, Caixa Postal 354, 96010-900 Pelotas-RS, <jesuspinto@terra.com.br>; ${ }^{3}$ Eng-0-Agr ${ }^{\circ}$., Ph.D., Pesquisador da EPAGRI; ${ }^{4}$ Eng - Agr ${ }^{\mathrm{a}}$., aluna do Programa de Pós-Graduação em Fisiologia Vegetal - UFPel; ${ }^{5}$ Aluno do curso de Agronomia - UFPel; ${ }^{6}$ Eng ${ }^{0}$-Agr ${ }^{\mathrm{o}}$, aluno do Programa de Pós-Graduação em Fitotecnia, Universidade Federal de Viçosa - UFV; ${ }^{7}$ Engo-Agroํo., aluno do Programa de Pós-Graduação em Sementes - UFPel. 
IRGA 422 CL, and the herbicide treatments were Only (imazethapyr+imazapic) at 0; (75+25); $(112.5+37.5)$ and $(150+50) \mathrm{g} \mathrm{ha}^{-1}$. Adjuvant Dash was added to the herbicide at $0.5 \% \mathrm{v} / \mathrm{v}$. The experiments were labeled as A1, A2 or A3, respectively, for one, two or three years of $C L$ rice. Grain sorghum, $c v . B R$ 304, was planted as a bioindicator of herbicide residue. The following parameters were evaluated: plant population, plant height; above ground biomass, 1000-grain weight and grain yield. As for grain sorghum plant height and 1000-seed weight, an interaction was observed between the different environments (years of $C L$ rice) and herbicide rate (imazethapyr+imazapic). For the other parameters, only effect for herbicide rat was detected. The results suggested that all grain sorghum parameters were affected by the herbicides (imazethapyr+ imazapic) in the soil. Grain sorghum injury increased with herbicide rate. In conclusion, grain sorghum, planted in rotation with rice is affected by the residue of the herbicide Only (imazethapyr+imazapic) applied to Clearfield ${ }^{\circledR}$ rice.

Keywords: Red rice, Clearfield ${ }^{\circledR}$ rice, imidazolinones, soil persistence.

\section{INTRODUÇÃO}

No Brasil, o sorgo granífero (Sorghum bicolor) foi introduzido no início do século XX, e a área cultivada, desde a sua introdução, tem mostrado flutuações a partir de dificuldades no processo de comercialização, geradas pela concorrência com a cultura do milho. Entretanto, relatos mais atuais têm destacado que a cultura tem apresentado expansão anual em torno de $20 \%$. Os maiores avanços, em área de cultivo, foram observados a partir de 1995, com incrementos nos plantios de sucessão a culturas de verão. O sorgo granífero, nessa modalidade de cultivo, tem demonstrado boa alternativa para produção de silagem, integrando-se ao sistema agropastoril. Além disso, essa cultura tem proporcionado maior proteção do solo contra a ação de fatores erosivos, além de propiciar condições para uso no plantio direto (Rodrigues \& Santos, 2006).

O sorgo granífero adapta-se a uma ampla gama de tipos de solo. No Brasil, a cultura é semeada desde os solos aluviais localizados nos vales das regiões semiáridas do Nordeste, passando pelos Latossolos das regiões do Cerrado, até os solos heteromórficos das regiões arrozeiras do RS (Rodrigues \& Santos, 2006). Nesta região, a cultura do sorgo tem sido utilizada na modalidade de rotação com arroz irrigado, tendo como objetivo principal a produção de alimento para animais domésticos, e ainda como cultura alternativa para controle de plantas daninhas. Dados estatísticos recentes apontam para uma ocupação de área, no Rio Grande do Sul, ao redor de $35 \mathrm{mil}$ ha e produção de 70 mil t (Garcia, 2006).
A rotação de culturas é um sistema que consiste em alternar, anualmente, espécies vegetais no decorrer do tempo numa mesma área agrícola, com vantagens e propósitos comerciais, e paralelamente atuar na conservação, recuperação, manutenção e/ou melhoria dos recursos naturais. Essa prática, quando adotada e conduzida de modo adequado por períodos suficientemente longos, reúne características potenciais que podem melhorar as condições físicas, químicas e biológicas do solo, através da reposição da matéria orgânica e da manutenção da estrutura, conservação de água e fertilidade. A rotação de culturas também pode auxiliar na redução de dominância de plantas daninhas de difícil controle e na incidência de pragas e doenças (Crookston et al., 1988).

As espécies vegetais envolvidas em um sistema de rotação de culturas devem atender tanto a exigências econômicas quanto ambientais, a fim de garantir a sustentabilidade do sistema. Nesse sentido, o planejamento é imprescindivel, pois as tecnologias a serem utilizadas devem ser praticadas conjuntamente, e as escolhas das culturas, assim como os sistemas de rotação, devem apresentar flexibilidade, de modo que atenda às particularidades regionais e às perspectivas de comercialização dos produtos. A variação de cultivos, utilizando culturas com diferentes hábitos de crescimento e exigências nutricionais, é o principal pressuposto da rotação para aumentar a estabilidade produtiva e maximizar economicamente a atividade agrícola. A troca de culturas na mesma estação de crescimento, em anos subsequentes, é uma constituinte importante 
e indispensável num programa integrado de manejo de plantas daninhas (Ball, 1992; Loeppky \& Derksen, 1994).

As inovações tecnológicas são desenvolvidas com o intuito de melhorar a produtividade dos sistemas de cultivos, porém elas podem causar alterações agroecológicas. Uma dessas inovações consiste na rotação de cultivos, ferramenta capaz de interferir no controle de plantas daninhas, na estrutura do solo, na ciclagem de nutrientes e na retenção de resíduos. Consequentemente, também pode interferir nos custos de produção, por exigir, por exemplo, maior quantidade de herbicidas (Fischer et al., 2002).

A rotação de cultivo de arroz irrigado (Oryza sativa) com soja (Glycine max), milho (Zea mays) ou sorgo granífero é uma prática eficiente no controle do arroz-vermelho, que auxilia na redução do banco de sementes e também contribui para a melhoria da produtividade da cultura do arroz, ao melhorar as condições químicas, físicas e estruturais do solo.

A utilização de herbicidas nos sistemas agrícolas não é isenta de riscos, pois seus resíduos poluem agroecossistemas e, muitas vezes, a sua fitotoxicidade pode causar interferências sobre plantas suscetiveis utilizadas como culturas em sistema de sucessão/rotação com a cultura tratada. O potencial de injúria às culturas sensíveis pode ser determinado pela persistência do herbicida no solo e pela suscetibilidade da cultura ao produto químico utilizado (Hartzler et al., 1989).

O controle eficaz de arroz-vermelho proporcionado pelo sistema Clearfield ${ }^{\circledR}$, associado às condições climáticas favoráveis, são os principais fatores que têm incrementado significativamente a produtividade nos três últimos anos de cultivo do arroz irrigado no Rio Grande do Sul. Diante do problema "arrozvermelho", essa nova tecnologia é incontestável. Entretanto, as instituições de pesquisa e extensão devem se manter em alerta, uma vez que vários estudos têm demonstrado que resíduos no solo de herbicidas do grupo das imidazolinonas podem interferir negativamente no crescimento e desenvolvimento de culturas suscetiveis utilizadas em sistema de rotação com tolerantes (Alister \& Kogan, 2005;
Barnes et al., 1989; Cantwell \& Slifek, 1989; Fleck \& Vidal, 1994; Gazziero et al., 1997; Loux \& Reese, 1993; Loux et al., 1989; Moyer \& Esau, 1996).

Este trabalho teve por objetivo avaliar a atividade residual da mistura formulada dos herbicidas (imazethapyr+imazapic) para a cultura do sorgo granifero, cv. BR 304, semeado em rotação com o arroz irrigado, conduzido pelo sistema Clearfield ${ }^{\circledR}$.

\section{MATERIAL E MÉTODOS}

Três experimentos com sorgo granífero, em rotação com arroz $\mathrm{Clearfield}^{\circledR}$, foram conduzidos em campo, em área experimental do Centro Agropecuário da Palma (CAP), da Universidade Federal de Pelotas (UFPel), no município de Capão do Leão, RS, no ano agrícola 2005/06. O solo da área experimental é classificado como Planossolo Háplico Eutrófico solódico, pertencente à Unidade de Mapeamento Pelotas (Embrapa, 2006).

Os resultados referentes a análises físicas e químicas do solo (Tabelas 1, 2, 3 e 4) serviram de diagnóstico para os procedimentos de correção de acidez do solo e manutenção de fertilidade, realizados conforme as recomendações para a cultura (Sosbai, 2007).

Os experimentos foram alocados em áreas contíguas e conduzidos pelo sistema de cultivo convencional, no primeiro ano de cultivo de arroz. A partir da primeira colheita (safra 2002/ $03)$, todas as culturas envolvidas na sucessão / rotação foram semeadas pelo sistema direto. Considerou-se o arroz como a cultura principal, o azevém como alternativa para outono e inverno e o sorgo como cultura substituinte do arroz no sistema de rotação. A dessecação das plantas de azevém, nos três experimentos, foi realizada com glyphosate na dose de 760 g i.a. ha-1 ${ }^{-1}$ quando $90 \%$ das plantas haviam atingido o ponto de maturação físiológica.

O delineamento experimental utilizado foi o de blocos ao acaso, com quatro repetições. Os tratamentos foram arranjados em esquema fatorial, em que o fator A compara o residual herbicida em diferentes ambientes, e o fator $\mathrm{B}$, o efeito de dose na atividade residual. As unidades experimentais constaram de parcelas de $15 \mathrm{~m}^{2}(5 \times 3 \mathrm{~m})$, reservando-se $8,8 \mathrm{~m}^{2}$ 
Tabela 1 - Diagnóstico para calagem do solo

\begin{tabular}{|c|c|c|c|c|c|c|c|c|c|}
\hline \multirow{2}{*}{ Registro } & $\begin{array}{c}\mathrm{pH} \\
\left(\mathrm{H}_{2} \mathrm{O}\right)\end{array}$ & $\mathrm{Ca}$ & $\mathrm{Mg}$ & $\mathrm{Al}$ & $\mathrm{H}+\mathrm{Al}$ & $\begin{array}{c}\mathrm{CTC} \\
\text { efetiva }\end{array}$ & \multicolumn{2}{|c|}{ Saturação (\%) } & \multirow{2}{*}{ Índice SMP } \\
\cline { 3 - 10 } & \multicolumn{3}{|c|}{$\left(\mathrm{cmol}_{\mathrm{c}} \mathrm{dm}^{-3}\right)$} & $\mathrm{Al}$ & Bases \\
\hline Amostra & 5,0 & 1,8 & 0,7 & 1,0 & 3,0 & 3,6 & 29 & 46 & 6,3 \\
\hline
\end{tabular}

Tabela 2 - Diagnóstico para recomendação de adubação NPK

\begin{tabular}{|c|c|c|c|c|c|c|c|}
\hline Registro & $\begin{array}{c}\% \text { Mat. Org. } \\
\mathrm{m} / \mathrm{v}\end{array}$ & $\%$ Argila & Textura & $\begin{array}{c}\text { P-Mehlich } \\
\left(\mathrm{mg} \mathrm{dm}^{-3}\right)\end{array}$ & P-Resina & $\begin{array}{c}\mathrm{CTC} \text { Ph 7 } \\
\left(\mathrm{cmol}_{\mathrm{c}} \mathrm{dm}^{-3}\right)\end{array}$ & $\begin{array}{c}\mathrm{K} \\
\left(\mathrm{mg} \mathrm{dm}^{-3}\right)\end{array}$ \\
\hline Amostra & 1,2 & 16 & 4,0 & 11,4 & --- & 5,5 & 17 \\
\hline
\end{tabular}

Tabela 3 - Diagnóstico para S, micronutrientes e relações molares

\begin{tabular}{|c|c|c|c|c|c|c|c|c|c|c|c|}
\hline \multirow{2}{*}{ Registro } & $\mathrm{S}$ & $\mathrm{Cu}$ & $\mathrm{Zn}$ & B & $\mathrm{Fe}$ & $\mathrm{Mn}$ & $\mathrm{Na}$ & \multicolumn{4}{|c|}{ Relações } \\
\hline & \multicolumn{7}{|c|}{$\left(\mathrm{mg} \mathrm{dm}^{-3}\right)$} & $\mathrm{Ca} / \mathrm{Mg}$ & $\mathrm{Ca} / \mathrm{K}$ & $\mathrm{Mg} / \mathrm{K}$ & $\mathrm{K} /(\mathrm{Ca}+\mathrm{Mg})$ \\
\hline Amostra & --- & 0,9 & 1,0 & --- & 13 & 17 & 17 & 2,5 & 43,6 & 17,8 & 0,027 \\
\hline
\end{tabular}

Tabela 4 - Análise granulométrica das amostras

\begin{tabular}{|c|c|c|c|c|}
\hline \multirow{2}{*}{ Registro } & \multicolumn{4}{|c|}{ Granulometria (\%) } \\
\cline { 2 - 5 } & Argila & Silte & Areia & Argila dispersa em água \\
\hline \multirow{2}{*}{ Amostra } & 15,4 & 41,4 & 43,2 & 9,6 \\
\hline
\end{tabular}

para a área de observação. As parcelas foram delimitadas por taipas, com finalidades específicas de proteção contra possiveis contaminações entre os tratamentos adjacentes e de manutenção do nível desejado da água de irrigação. O cultivar de arroz semeado foi o IRGA $422 \mathrm{CL}$, e os tratamentos herbicidas foram a mistura formulada de (imazethapyr+ imazapic) a $0,(75+25),(112,5+37,5)$ e $(150+50)$ g i.a. ha ${ }^{-1}$, acrescidos de adjuvante $\operatorname{Dash}^{\circledR}$ a 0,5\% v/v. Doravante, os tratamentos serão representados pela soma de i. a. dos dois herbicidas contidos no produto comercial denominado "Only" e aplicados ao arroz CL (0, 100, 150 e $200 \mathrm{~g} \mathrm{ha}^{-1}$ ). Os herbicidas foram aplicados em pós-emergência, nas três safras, quando o arroz se encontrava nos estádios fenológicos V3-V4 (Sosbai, 2007), utilizandose um pulverizador costal pressurizado a $\mathrm{CO}_{2}$, munido de quatro bicos do tipo leque (110.02) e à pressão constante de $210 \mathrm{kPa}$, que proporcionaram a aplicação de um volume de calda herbicida equivalente a $160 \mathrm{~L} \mathrm{ha}^{-1}$. A irrigação permanente do arroz foi mantida a partir do sexto, sétimo e décimo primeiro dias após a aplicação dos tratamentos herbicidas nas safras 2002/03, 2003/04 e 2004/05, respectivamente. Os experimentos ou ambientes foram denominados A1, A2 e A3, respectivamente para um, dois e três anos de cultivo de arroz irrigado pelo sistema Clearfield ${ }^{\circledR}$, repetidos em mesma área, mantendo-se o mesmo 
croqui e um único sorteio dos tratamentos nos diferentes anos de duração de cada experimento. Para detectar a ocorrência de resíduo de herbicidas no solo, deixado pelos herbicidas no cultivo de arroz conduzido pelo sistema Clearfield $^{\circledR}$, foi utilizado o sorgo granífero, cv. BR 304, como espécie indicadora. O sorgo foi semeado em 26/11/2005 no sistema direto, utilizando-se uma semeadora-adubadora com espaçamento de $45 \mathrm{~cm}$ entre fileiras, regulada para distribuir nove sementes aptas por metro linear. A emergência da cultura ocorreu aos 11 dias após a semeadura, e aos 18 dias foi realizado o desbaste, com arranque manual do excesso de plantas, mantendo-se uma população estimada de 200 mil plantas ha $^{-1}$. O controle de plantas daninhas e de insetos na cultura do sorgo foi realizado, respectivamente, com o herbicida atrazina $\left(2,5 \mathrm{~kg} \mathrm{ha}^{-1}\right)$ e o inseticida spinosade (24 $\left.\mathrm{g} \mathrm{ha}^{-1}\right)$.

As variáveis-resposta consideradas neste trabalho foram: população de plantas e estatura média, rendimento biológico, peso de mil grãos e produtividade do sorgo. As avaliações das populações inicial e final foram realizadas pela contagem de plantas emergidas. A primeira foi feita aos sete dias após a emergência (DAE). Nessa ocasião, fez-se o desbaste em todas as parcelas, procurando-se obter máxima equidistância entre nove plantas selecionadas por metro de fileira e o estande inicial de 200 plantas ha-1. O levantamento da população final foi realizado aos $35 \mathrm{DAE}$ e repetido por ocasião da medição da estatura de plantas. Os dados referentes à altura de plantas foram considerados a partir do colo da planta até a base da folha-bandeira. Eles foram obtidos em amostras de dez plantas por repetição, selecionadas ao acaso, aos $80 \mathrm{DAE}$. No tratamento testemunha, nessa ocasião, $10 \%$ das plantas já haviam iniciado a emissão da panícula. Os dados referentes ao rendimento biológico foram gerados a partir da massa seca de 20 plantas amostradas ao acaso na população que constituía a massa verde da área útil de cada parcela, quando as plantas apresentavam grãos de consistência leitosa. Para avaliar o peso de mil grãos (P1000) de sorgo, foram tomadas amostras das quatro repetições por tratamento e delas retiradas ao acaso oito amostras de 100 grãos, conforme regras para análise de sementes (Brasil, 1992), e pesadas em balança analítica. Os dados referentes à variável-resposta produtividade de grãos de sorgo foram quantificados pela colheita da área central de $5,4 \mathrm{~m}^{2}$ $(1,35 \times 1,35 \mathrm{~m})$, quando o teor de umidade dos grãos aproximou-se de $23 \%$. Os dados referentes à variável-resposta produtividade foram obtidos a partir da massa de grãos produzida por parcela e corrigida para $13 \%$ de umidade.

Os dados gerados no experimento foram submetidos à análise da variância $(\mathrm{p} \leq 0,05)$; havendo significância, eles foram analisados por modelos de regressão polinomial (Machado \& Conceição, 2007).

\section{RESULTADOS E DISCUSSÃO}

Nos três experimentos, ocorreu significância estatística para doses de (imazethapyr+ imazapic) e interação com ambientes para as variáveis: população de plantas (Figura 1A), estatura de planta (Figura 1B) e peso de mil grãos (Figura 2B), enquanto rendimento biológico (Figura 2A) e produtividade de grãos (Figura 3) mostraram significância estatística somente para doses do herbicida.

As populações médias de plantas de sorgo obtidas em cada ambiente ajustaram-se a equações lineares (Figura 1A), cujos valores do coeficiente de determinação $\left(\mathrm{R}^{2}\right)$ foram de $0,92,0,88$ e 0,88 , respectivamente para $\mathrm{A} 1$, A2 e A3, demonstrando adequação dos dados ao modelo utilizado. As inclinações das curvas geradas pelas equações mostram que o cultivo de arroz no sistema Clearfield ${ }^{\circledR}$ deixou resíduos dos herbicidas (imazethapyr+imazapic) no solo ao reduzir a população de plantas de sorgo semeado na mesma estação de crescimento, no ano subsequente ao cultivo de arroz. O sorgo, até os 7 DAE, não se mostrou afetado pelos tratamentos, apresentando população média de 215 mil plantas, com variação equivalente a $11 \%$ para mais ou para menos em relação ao tratamento testemunha. A germinação e emergência normal do sorgo eram esperadas, uma vez que o efeito residual desses compostos no solo, em doses baixas, na maioria das culturas, não influencia a germinação e emergência das plantas (Shaw \& Wixson, 1991; Alister \& Kogan, 2005). Entretanto, entre 7 e 35 dias após o desbaste, em todos os ambientes, foram observadas reduções significativas na população de sorgo em todos os tratamentos com (imazethapyr+ 
imazapic), mais evidenciadas à medida que foram ocorrendo aumentos na dose dos herbicidas. Também pode ser observado que os resíduos deixados pelos tratamentos (imazethapyr+ imazapic) na dose de $100 \mathrm{~g} \mathrm{ha}^{-1}$ foram letais para 30,50, 21,40 e 23,50\% das plantas a partir da população corrigida respectivamente nos ambientes A1, A2 e A3 (Figura 1A). Quando a dose foi aumentada para $200 \mathrm{~g} \mathrm{ha}^{-1}$, o percentual de plantas mortas aumentou para $61,10 \%$ no $A 1,42,70 \%$ no A2 e $46,90 \%$ no A3. Esses resultados mostram que a mistura comercial de imazethapyr+imazapic, aplicada na dose de $100 \mathrm{~g} \mathrm{ha}^{-1}$, recomendada para o arroz Clearfield $^{\circledR}$, deixa resíduo no solo e pode afetar negativamente a densidade populacional do sorgo granífero, cv. BR 304, semeado em mesma estação de crescimento do ano seguinte. Vários trabalhos têm sido desenvolvidos no sentido de avaliar a persistência no solo de herbicidas do grupo das imidazolinonas. Em trabalho realizado por Fleck \& Vidal (1994) foi observado que os herbicidas imazethapyr e imazaquin aplicados na soja deixaram resíduos suficientes para reduzir em 62 e $75 \%$, respectivamente, a população de plantas na cultura do girassol. O longo período de atividade da mistura herbicida (imazethapyr+imazapic) encontrado neste trabalho assemelha-se ao de resultados antecedentes que também demonstram a persistência no solo destes e outros herbicidas do grupo químico das imidazolinonas (Bashan et al., 1987; Goetz et al., 1990; Loux \& Reese, 1993; Alister \& Kogan, 2005).
Os resultados obtidos para estatura média de planta, nos três anos, encontram-se representados por equações lineares (Figura 1B), cujos valores do coeficiente de determinação $\left(R^{2}\right)$ variaram de 0,92 a 0,89 , demonstrando ajuste dos dados ao modelo utilizado.

Os valores obtidos para estatura de plantas mostram que essa variável foi afetada negativamente pelo resíduo dos herbicidas. O crescimento de plantas ocorreu na razão inversa ao residual correspondente a acréscimos na dose da mistura herbicida. Incrementos de $50 \mathrm{~g}$ na dose de (imazethapyr+imazapic) elevaram a atividade residual do herbicida, reduzindo em 13,2, 7,95 e 11,15 cm a estatura média de planta, respectivamente para os ambientes A1, A2 e A3. Plantas com menor estatura, comparativamente ao tratamento testemunha, também foram observadas nas culturas de milho e pepino, semeadas 150 dias após a aplicação do herbicida imazethapyr, na dose de $200 \mathrm{~g} \mathrm{ha}^{-1}$ (Gazziero et al., 1997). Em outro estudo foi demonstrado que as culturas do sorgo e milho têm as respectivas taxas de crescimento reduzidas, em altura, se forem semeadas em sucessão à cultura da soja, até 150 dias após a aplicação de imazethapyr, nas doses de 100 e $150 \mathrm{~g} \mathrm{ha}^{-1}$ (Silva et al., 1999).

Em P1000, similarmente à população e estatura de plantas, os dados obtidos também mostraram significância estatística para a interação entre doses do herbicida (imazethapyr+ imazapic) e ambiente (A1, A2

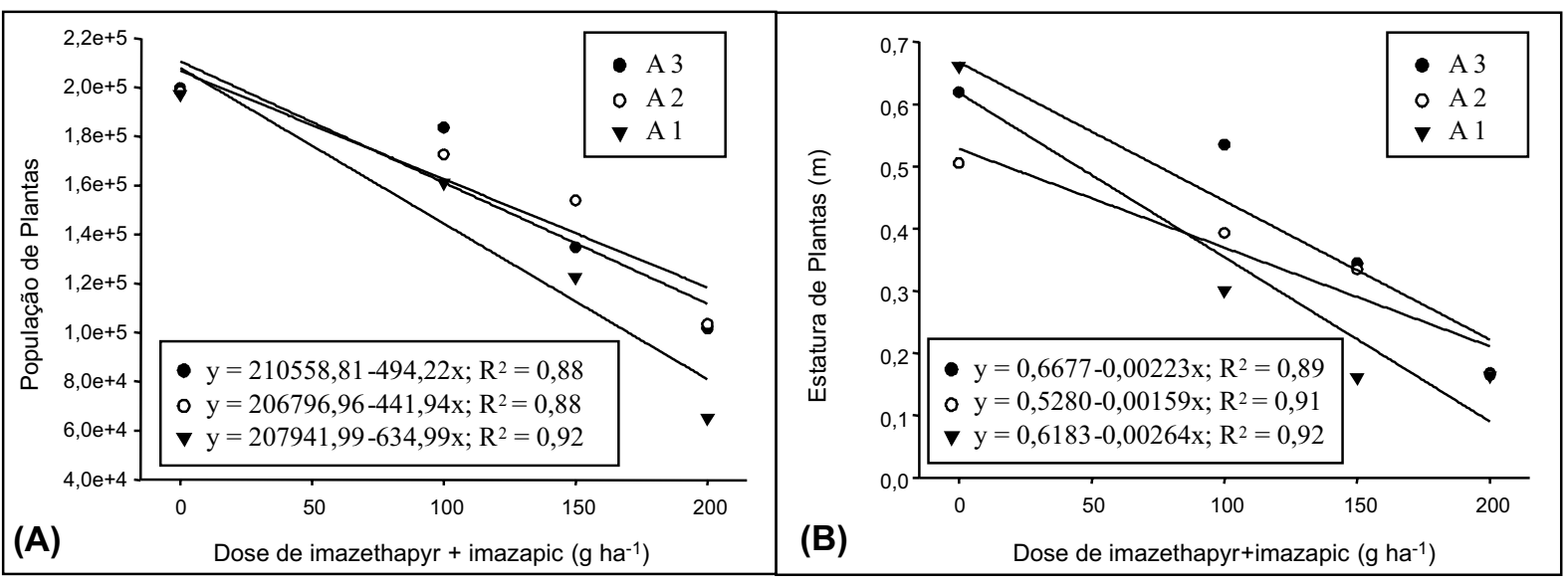

Figura 1 - População de plantas (A) e estatura de plantas (B) do sorgo granífero, semeado em rotação com o arroz Clearfield ${ }^{\circledR}$, sendo A1, A2 e A3 os ambientes com anos de cultivo com arroz Clearfield ${ }^{\circledR}$. CAP-UFPel, Capão do Leão-RS, 2007. 
e A3). Os valores encontrados para os três ambientes ajustaram-se às equações lineares cujos valores do coeficiente de determinação $\left(R^{2}\right)$ variaram de 0,79 a 0,99, indicando ajuste dos dados ao modelo, e representadas pelas curvas correspondentes (Figura 2B). Os resultados mostraram que o P1000 do sorgo foi afetado pelos herbicidas (imazethapyr+ imazapic), cuja permanência de atividade no solo se manteve por um período superior a 365 DAA e em quantidade suficiente para reduzir significativamente a massa de grãos. Seguindo a tendência das demais variáveis estudadas, o P1000 diminuiu à medida que foi aumentada a dose do herbicida. Os herbicidas (imazethapyr+imazapic) aplicados na dose de $100 \mathrm{~g} \mathrm{ha}^{-1}$ reduziram em 29,5, 10,2 e 17,9\% o P1000, respectivamente nos ambientes A1, A2 e A3, enquanto nos tratamentos em que foi aplicado o dobro da dose recomendada a atividade residual remanescente do herbicida reduziu o P1000, naquela mesma ordem, em $59,20,5$ e $35,8 \%$.

Além dos efeitos negativos com o aumento da dose na população de plantas (Figura 1A), na estatura de planta (Figura $1 \mathrm{~B}$ ) e na massa do grão (Figura 2B) nos três ambientes, a pesquisa também mostrou que essas variáveis foram mais alteradas no A1, comparativamente aos demais ambientes, em quaisquer das doses testadas. Esses resultados conduzem a descartar a hipótese de que a adoção do sistema de arroz Clearfield ${ }^{\circledR}$ por duas a três safras consecutivas possa acumular atividade herbicida no solo, pelo menos, em quantidades possiveis de serem detectadas pela sensibilidade do sorgo, embora alguns trabalhos com esses e outros compostos do grupo químico das imidazolinonas, ao serem avaliados, através de testes com plantas sensiveis, tenham mostrado persistência no solo superior a 300 dias para tomateiro e pimenta-malagueta (Alister $\&$ Kogan, 2005), de 780 dias para batata (Hart et al., 1991) e de 540 dias para trigo e cevada (Hart et al., 1991; Ball et al., 2003).

Esses resultados podem ser explicados se for considerado que a palha pode ter interferido no processo de degradação do herbicida, uma vez que a espessura da camada de palha ficou assim distribuída: $\mathrm{A} 1<\mathrm{A} 2<\mathrm{A} 3$, em função do número de safras diferenciadas com semeadura direta. A semeadura direta, devido à não mobilização do solo e à manutenção deste com cobertura de palha, eleva o conteúdo superficial de matéria orgânica e reduz as amplitudes de temperatura e umidade do solo. Em razão disso, incrementam-se a massa, a atividade microbiana e a biotransformação das moléculas do herbicida no solo (Weed et al., 1995; Reddy et al., 1995). Outro aspecto que deve ser considerado é que as diferenças, entre ambientes, nas quantidades de palha encontradas nas coberturas também constituíram barreiras diferentes entre a pulverização e o solo. Então, é provável que maiores quantidades de herbicida tenham ficado retidas na palha em A1 e A2 por sete dias, periodo que antecedeu a irrigação por inundação da lavoura. Se for considerada a possibilidade de retenção parcial do herbicida na palha, conjetura-se também a possibilidade de que parte deste tenha sido degradada por fotólise em função do longo tempo de exposição à luz. Além da atividade microbiana, a fotólise, sob determinadas condições, também pode ser considerada uma fonte de degradação das imidazolinonas. Esse segundo caminho para a degradação dos herbicidas imazaquin e imazethapyr foi sugerido por Bashan \& Levy (1987) e confirmado por Renner et al. (1988), Goetz et al. (1990) e Curran et al. (1992), ao observarem que a degradação de imazaquin e imazethapyr ocorria muito mais rapidamente na superficie do solo, comparativamente ao incorporado.

Para a variável-resposta rendimento biológico, os valores médios por ambiente estão representados por uma equação linear, cujo coeficiente de determinação $\left(R^{2}=0,97\right)$ indica que os dados se ajustaram ao modelo utilizado (Figura 2A). Essa variável também mostra que os herbicidas (imazethapyr+imazapic) permaneceram com atividade no solo com intensidade variável com a dose e sem interferência do ambiente. A curva mostra que os herbicidas remanescentes da degradação (imazethapyr+imazapic), aplicados na dose recomendada de $100 \mathrm{~g} \mathrm{ha}^{-1}$ ao arroz Clearfield ${ }^{\circledR}$, reduziram em $38,1 \%$ o rendimento total de massa seca do sistema aéreo do sorgo, enquanto o dobro da dose recomendada elevou o percentual de redução para $76,2 \%$. O rendimento biológico do sorgo - a exemplo do resultado das demais variáveis anteriormente descritas e discutidas - também mostra que a 
atividade residual de (imazethapyr+imazapic) permaneceu no solo por um período que pode atingir plantas sensiveis semeadas na mesma estação de crescimento do ano seguinte à sua aplicação. Os resultados observados para essa variável confirmam estudos envolvendo rotação de milho Clearfield ${ }^{\circledR}$ com 11 espécies cultivadas. Nesse trabalho, os autores destacaram nos resultados que, das 11 culturas semeadas aos 300 dias após a aplicação dos herbicidas, nove tiveram redução no crescimento e desenvolvimento, incluídos produção de massa e rendimento, afetados pela atividade residual de imazapyr+imazapic ou imazapyr+imazethapyr (Alister \& Kogan, 2005). Em trabalho realizado por Silva et al. (1999) também foi observada forte inibição na produção de massa seca da parte aérea e da raiz quando a cultura do sorgo foi semeada aos 60 após a aplicação de imazethapyr. No mesmo trabalho, os autores relataram que o dobro da dose recomendada (200 $\mathrm{g} \mathrm{ha}^{-1}$ ) do herbicida causou inibição do crescimento quando a cultura foi semeada até 120 DAA.

A variável-resposta produtividade de grãos (Figura 3), à semelhança do rendimento biológico, mostrou significância estatística somente para herbicidas (doses). Os valores médios obtidos para os três ambientes se ajustam a uma equação linear, cujo coeficiente de determinação $(R=0,99)$ mostra que o modelo é representativo. A curva mostra que a produtividade de grãos decresceu linearmente com o aumento da dose dos herbicidas (imazethapyr+ imazapic). A dose recomendada (100 $\left.\mathrm{g} \mathrm{ha}^{-1}\right)$ da mistura desses herbicidas, aplicada à cultura do arroz, permaneceu no solo até a estação de crescimento do ano seguinte e em quantidade suficiente para reduzir em $37,9 \%$ a produtividade do sorgo. As perdas foram ainda maiores nos tratamentos que receberam uma vez e meia e o dobro da dose recomendada. Nessas duas situações, a produtividade do sorgo teve reduções médias de 56,97 e 75,96\%, respectivamente. Esses estudos corroboram outras pesquisas que também mostraram a elevada persistência de herbicidas do grupo químico das imidazolinonas reduzindo a produtividade de culturas sensiveis, semeadas ou transplantadas, em sucessão a culturas tolerantes. Em trabalhos realizados por Alister \& Kogan (2005) também foram observadas reduções significativas no rendimento de grãos nas culturas de aveia e cevada cervejeira semeadas aos 135 DAA de imazapyr+imazapic ou imazapyr+ imazethapyr, aplicados ao milho Clearfield $^{\circledR}$. Queda em rendimento também foi observada por Moyer \& Esau (1996) nas culturas de linho, milho, girassol e trigo semeadas em até um ano após a aplicação de $200 \mathrm{~g} \mathrm{ha}^{-1} \mathrm{de}$ imazethapyr; esses autores afirmaram que a atividade residual desse herbicida pode permanecer no solo e reduzir o rendimento de canola e beterraba-açucareira em até 720 e 1.080 dias após a aplicação, respectivamente. A elevada permanência no solo da mistura de (imazethapyr+imazapic), com agressividade

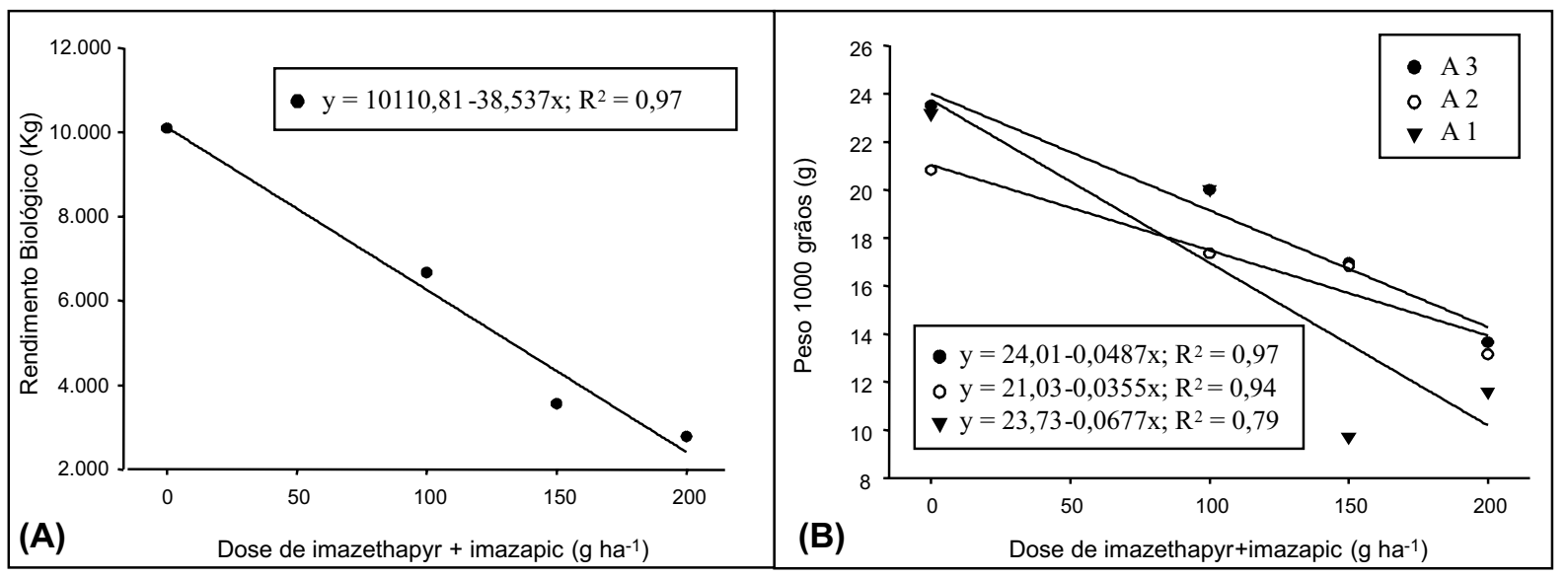

Figura 2 - Rendimento biológico (A) e massa de mil grãos (B) do sorgo granífero, semeado em rotação com o arroz Clearfield ${ }^{\circledR}$, sendo $\mathrm{A} 1, \mathrm{~A} 2$ e $\mathrm{A} 3$ os ambientes que representam os anos de cultivo com arroz Clearfield ${ }^{\circledR}$. CAP-UFPel, Capão do Leão-RS, 2007. 


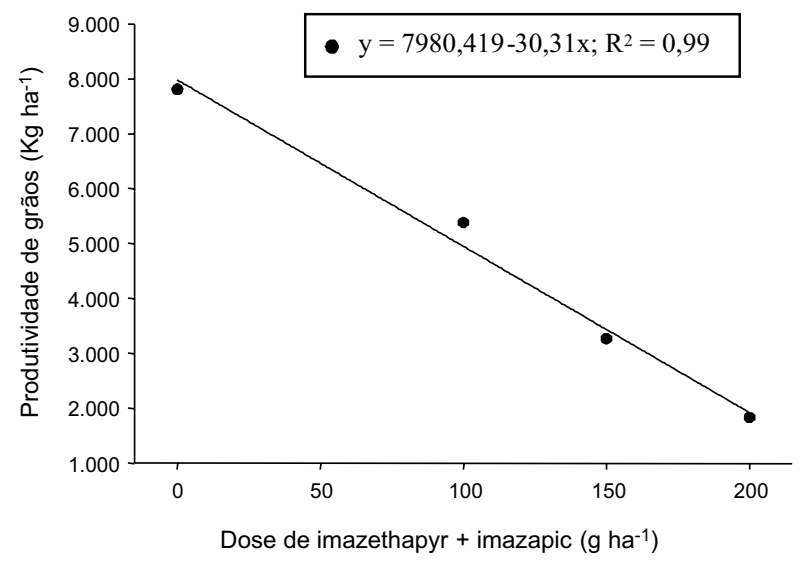

Figura 3 - Produtividade de grãos da cultura do sorgo granífero, semeado em rotação com o arroz Clearfield ${ }^{\circledR}$. CAP-UFPel, Capão do Leão-RS, 2007.

herbicida para o sorgo, pode ser atribuída em parte ao imazapic. Esse indicativo tem por base estudos realizados em casa de vegetação, quando foi demonstrado que somente $13 \mathrm{~g}^{\text {ha-1 }}$ de imazapic foram suficientes para reduzir o acúmulo de massa verde em diferentes estruturas de trigo, milho, sorgo e azevém (Shaw \& Wixson, 1991). Estes autores afirmaram que a elevada atividade residual de imazethapyr+ imazapic é assegurada por sinergismo, quando o imazapic é misturado a outros herbicidas do grupo das imidazolinonas.

Confirmou-se com este trabalho que o sorgo granifero cv. BR 304 é uma espécie sensivel à mistura formulada dos herbicidas (imazethapyr+imazapic), podendo ser utilizada como cultura indicadora para detectar, no solo, a permanência de atividade dessa mistura herbicida. Essa mistura na dose de $(75+25) \mathrm{g} \mathrm{ha}^{-1}-1,0 \mathrm{~L} \mathrm{ha}^{-1}$ da formulação comercial - aplicada em pós-emergência do arroz irrigado - manteve atividade no solo por tempo suficiente para reduzir a população e altura média de plantas, o rendimento biológico, o peso de mil grãos e a produtividade do sorgo granífero, cv. BR 304, semeado em rotação, após um ano de cultivo de arroz Clearfield $^{\circledR}$.

O sorgo granífero, cv. BR 304, não deve ser recomendado em sistemas de rotação de culturas, semeado em mesma estação de crescimento, subsequente ao arroz Clearfield ${ }^{\circledR}$.

\section{LITERATURA CITADA}

ALISTER, C.; KOGAN, M. Efficacy of imidazolinone herbicides applied to imidazolinone-resistant maize and their carryover effect on rotational crops. Crop Protec., v. 24, p. $375-379,2005$.

BALL, D. A. Weed seedbank response to tillage, herbicides, and crop rotation sequence. Weed Sci., v. 40, p. 654-659, 1992.

BALL, D. A.; YENISH, J. P.; ALBY, T. Effect of imazamox soil persistence on dryland rotational crops. Weed Technol., v. 17, n. 1 p. 161-165, 2003.

BASHAM, G.; LAVY, T. L.; OLIVER, L. R.; SCOTT, H. D. Imazaquin persistence and mobility in three Arkansas soils. Weed Sci., v. 35, p. 576-582, 1987

BASHAM, G.; LAVY, T. L. Microbial and photolytic dissipation of imazaquin in soil. Weed Sci., v. 35, p. 865-870, 1987.

BARNES C. J.; GOETZ, A. J.; LAVY, T. L. Effects of imazaquin residues on cotton (Gossypium hirsitum). Weed Sci., v. 37, n. 6, p. 820-824, 1989.

BRASIL - Ministério da Agricultura, do Abastecimento e da Reforma Agrária. Secretaria Nacional de Defesa Agropecuária. Regras para Análise de Sementes. Brasília, 1992. 365 p.

CANTWELL, J. R.; SLIFEK, F. W. Biodegradation characteristics of imazaquin and imazethapyr. Weed Sci., v. 37 , p. $815-819,1989$

CROOKSTON, R. K.; KURLE, J. E.; LUESCHEN, W. E. Relative ability of soybean, fallow and triacontanol to alleviate yield reductions associated with growing corn continuously. Crop Sci., v. 28, p. 145-147, 1988.

CURRAN, W. S.; LIEBL, R. A.; SIMMONS, P. W. Effects of tillage and application method on clomazone, imazaquin, and imazethapyr persistence. Weed Sci., v. 40, p. 484-489, 1992.

EMPRESA BRASILEIRA DE PESQUISA AGROPECUÁRIA - EMBRAPA, Centro Nacional de Pesquisa de Solos. Sistema Brasileiro de Classificação de Solos. Rio de Janeiro: Embrapa Solos, 2006. 306 p.

FISCHER, R. A.; SANTIVERI, F.; VIDAL, I. R. Crop rotation, tillage and crop residue management for wheat and maize in the sub-humid tropical highlands I. wheat and legume performance. Field Crops Research, v. 79, p. 107-122, 2002.

FLECK, N. G.; VIDAL, R. A. Injúria potencial de herbicidas de solo ao girassol. III: imazaquin e imazethapyr.

Planta Daninha, v. 12, n. 1, p. 39-43, 1994. 
GARCIA, J. C. Cultivo do sorgo, versão eletrônica, 2.ed., 2006, <http://www.cnpms.embrapa.br/publicacoes/sorgo/ coeficientestecnicos.htm>, acessado em 13/07/2007.

GAZZIERO, D. L. P. et al. Persistência dos herbicidas imazaquin e imazethapyr no solo e os efeitos sobre plantas de milho e pepino. Planta Daninha, v. 15, n. 2, p. 162-169, 1997

GOETZ, A. J.; LAVY, T. L.; GBUR JR, E. E. Degradation and field persistence of imazethapyr. Weed Sci., v. 38, n. 4-5, p. $421-428,1990$.

HART, R.; LIGNOWSKI, E.; TAYLOR, R. Imazethapyr herbicide. In: SHANER, D. L.; CONNOR, S. L. Eds. The imidazolinone herbicides. Boca Raton, CRC Press, 1991. p. $247-256$

HARTZLER, R. G.; FAWCET, R. S.; OWEN, D. K. Effects of tillage on trifluralin residue carryover injury to corn (Zea mays). Weed Sci., v. 37, n. 4, p. 609-615, 1989.

LOEPPKY, H. A.; DERKSEN, D. A. Quackgrass suppression through crop rotation in conservation tillage systems. Can. J. of Plant Sci., v. 74, p. 193-197, 1994.

LOUX, M. M.; LIEBEL, A.; SLIFE, F. W. Adsorption of imazaquin and imazethapyr on soils, sediments and selected adsorbents. Weed Sci., v. 37, p. 712-718, 1989

LOUX, M. M.; REESE, K. D. Effect of soil type and pH on persistence and carryover of imidazolinone herbicides. Weed Technol., v. 7, n. 2, p. 452-458, 1993.

MACHADO, A. A.; CONCEIÇÃO, A.R. Sistema de Análise Estatística para Windows - WINSTAT (versão 1.0). Pelotas: Núcleo de Informação Aplicada - Universidade Federal de Pelotas, 2007.
MOYER, J. R.; ESAU, R. Imidazolinone herbicide effects on following rotational crops in Southern Alberta. Weed Technol., v. 10, p. 100-106, 1996

REDDY, K. N.; ZABLOTOWICZ, R. M.; LOCKE, M. A. Chlorimuron adsorption, desorption and degradation in soils from conventional tillage and no-tillage systems. J. Environ. Quality, v. 24, p. 760-767, 1995.

RENNER, K. A.; MEGITT, W. F.; PENNER, D. Effect of soil $\mathrm{pH}$ on imazaquin and imazethapyr adsorption to soil and phytoxicity to corn (Zea mays). Weed Sci., v. 36, n. 1, p. $78-83,1988$.

RODRIGUES, J. A. S.; SANTOS, F. G. Cultivo do sorgo, versão eletrônica, 2.ed., 2006, <http://

www.cnpms.embrapa.br/publicacoes/sorgo/autores.htm>, acessado em 13/07/2007.

SILVA, A. A.; OLIVEIRA Jr., R. S.; COSTA, E. R.; FERREIRA, L. R. Efeito residual no solo dos herbicidas imazamox e imazethapyr para as culturas de milho e sorgo. Planta Daninha, v. 17, n. 3, p. 345-354, 1999.

SOSBAI (Sociedade Sul Brasileira de Arroz irrigado). Arroz irrigado: recomendações técnicas da pesquisa para o Sul do Brasil. Pelotas: Sosbai/ Embrapa Clima Temperado, 2007. $164 \mathrm{p}$

SHAW, D.; WIXSON, M. Postemergence combinations of imazaquin of imazethapyr with AC 263, 222 for weed control in soybean (Glycine max). Weed Sci., v. 39, p. 644-649, 1991.

WEED, D. A. J. et al. Dissipation and distribution of herbicides in the soil profile. J. Environ. Quality, v. 24, n. 1, p. $68-79,1995$ 